\title{
Amyloid Plaques and Symptoms of Depression Links to Medical Help-Seeking due to Subjective Cognitive Decline
}

\author{
Ragna Espenes $^{\mathrm{a}, \mathrm{b}, *}$, Bjørn-Eivind Kirsebom ${ }^{\mathrm{a}, \mathrm{b}}$, Cecilia Eriksson $^{\mathrm{c}, \mathrm{d}}$, Knut Waterloo ${ }^{\mathrm{a}, \mathrm{b}}$, Erik Hessen ${ }^{\mathrm{c}, \mathrm{d}}$, \\ Stein Harald Johnsen ${ }^{\mathrm{a}, \mathrm{e}}$, Per Selnes ${ }^{\mathrm{c}, \mathrm{f}}$ and Tormod Fladby ${ }^{\mathrm{c}, \mathrm{f}}$ \\ ${ }^{a}$ Department of Neurology, University Hospital of North Norway, Troms $\phi$, Norway \\ ${ }^{\mathrm{b}}$ Department of Psychology, Faculty of Health Sciences, UiT The Arctic University of Norway, Troms $\phi$, Norway \\ ${ }^{\mathrm{c}}$ Department of Neurology, Akershus University Hospital, Lørenskog, Norway \\ ${ }^{\mathrm{d}}$ Department of Psychology, University of Oslo, Oslo, Norway \\ ${ }^{\mathrm{e}}$ Department of Clinical Medicine, Faculty of Health Sciences, UiT The Arctic University of Norway, \\ Troms $\phi$, Norway \\ ${ }^{\mathrm{f}}$ Institute of Clinical Medicine, Campus Ahus, University of Oslo, Oslo, Norway
}

\begin{abstract}
.
Background: Subjective cognitive decline (SCD) is associated with an increased risk of Alzheimer's disease (AD). However, patients reporting SCD to their general practitioner are not always referred to a memory clinic.

Objective: To investigate whether prior history of medical help-seeking is associated with AD biomarker abnormality, worse cognitive performance, and/or depressive symptoms in SCD.

Methods: We compared levels of cerebrospinal fluid (CSF) A $\beta_{1-42}$, cognitive performance, and depressive symptoms (15item Geriatric Depression Scale, GDS-15) between healthy controls $(n=88)$, SCD with a history of medical help seeking (SCD-HS, $n=67$ ), and SCD non help-seekers (SCD-NHS, $n=44)$. Cases with evidence of amyloid plaques (CSF A $\beta_{1-42}$ $\leq 708 \mathrm{ng} / \mathrm{l})$ and symptoms of depression (GDS-15 $\geq 6$ ) were determined in both SCD groups.

Results: The SCD-HS group had lower CSF A $\beta_{1-42}(p<0.01)$, lower word list learning and memory recall $(p<0.0001)$, and an increased level of depressive symptoms $(p<0.0001)$ compared to controls and SCD-NHS cases. The SCD-HS group had more cases with symptoms of depression $(n=12,18 \%)$ and amyloid plaques $(n=18,27 \%)$ compared to SCD-NHS $(n=1$, $2 \%$ and $n=7,16 \%$, respectively). None of the SCD-HS cases and only one SCD-NHS case had concurrent symptoms of depression and amyloid plaques. The SCD-HS cases showed equal word list learning and memory performance regardless of amyloid status or symptoms of depression.

Conclusion: Medical help-seeking in SCD is associated with an increased risk of AD pathology or symptoms of depression. However, subtle memory deficits are seen in SCD help-seekers, also without amyloid plaques or symptoms of depression.
\end{abstract}

Keywords: Alzheimer's disease, amyloid plaques, cerebrospinal fluid $A \beta_{1-42}$, cognitive symptoms, early diagnosis, helpseeking behavior, medical help-seeking, neuropsychiatric symptoms, neuropsychological tests, subjective cognitive decline

\section{INTRODUCTION}

\footnotetext{
${ }^{*}$ Correspondence to: Ragna Espenes, Department of Psychology, Faculty of Health Sciences, UiT The Arctic University of Norway, 9037 Troms $\varnothing$, Norway. Tel.: +47 95206541; E-mail: Ragna.Espenes@uit.no.
}

Studies have shown that the pathophysiological underpinnings of Alzheimer's disease (AD) may begin 10 to 15 years before the emergence of detectable mild cognitive impairment (MCI) [1, 2]. 
This extended preclinical phase constitutes a possible window for preventive interventions $[1,3]$. Improved methods for earlier identification of $\mathrm{AD}$ in the preclinical phase are therefore needed. Subjective cognitive decline (SCD), the self-perceived decline in cognitive functions while performing within the normal range on cognitive tests, is associated with an increased risk of MCI and dementia due to AD [4-10]. Indeed, the presence of amyloid plaques, a hallmark of $\mathrm{AD}$, in cognitively healthy persons with SCD has shown to predict later decline in memory functions [11-13]. Moreover, SCD may be accompanied by functional alterations in hippocampal integrity reflecting compensatory mechanisms that preserve memory performance [14].

However, SCD is heterogeneous, often a benign condition, and most cases do not progress to dementia $[4,5,15-19]$. A recent study found increased levels of stress/depressive symptoms in SCD with a low prevalence of altered CSF AD biomarkers over time, suggesting that $\mathrm{AD}$ is not the most frequent etiology [15]. At present, $\mathrm{AD}$ is assessed using cerebrospinal fluid (CSF) or positron emission tomography (PET) imaging analyses, procedures which are invasive or costly. Thus, methods to improve the detection of SCD cases with incipient AD are of value for the selection of candidates eligible for early intervention trials.

Recruitment of MCI and SCD participants through memory clinics include individuals with higher rates of abnormal CSF biomarkers and increased brain amyloid- $\beta(\mathrm{A} \beta)$ deposition as compared to selfreferred participants from the community [20-23]. We and others have shown that MCI recruited through memory clinics also have poorer cognitive function than community samples [21, 24, 25]. However, while memory clinic SCD cases have shown higher conversion rates to MCI compared to community cases $[23,26]$, and lower baseline cognitive performance in one study [27], most studies have not found any baseline cognitive differences in SCD cases due to recruitment source bias [22, 24, 26]. The biases observed from recruiting memory clinic SCD cases may stem from worries or concerns felt by either patients, or their families reaching a threshold prompting the person to seek medical help. Indeed, worried individuals with SCD have increased risk of developing objective cognitive decline [6, 28, 29]. However, patients who report SCD to their general practitioner (GP) may not be referred to a memory clinic for assessment [30]. In a previous study, we found no significant cognitive differences between
SCD cases recruited from memory clinics as compared to SCD cases recruited from a community sample [24].

In the present study, we hypothesize that SCD cases with a history of medical help-seeking, independent of recruitment source, carry a higher risk of $\mathrm{AD}$ compared to non-help-seeking SCD cases and healthy controls. We compare levels of CSF AD biomarkers $\left(A \beta_{1-42}\right.$, total tau, and phosphorylated tau) and cognitive performance between these groups. In addition, we investigate levels of depressive symptoms between groups, as depressive symptoms may play a role in the expression of SCD as well as medical help-seeking. Lastly, we investigate the association between pathological CSF $A \beta_{1-42}$ levels (e.g., the presence of amyloid plaques) and frequencies of cases with symptoms of depression (15-item Geriatric Depression Scale (GDS-15) $\geq 6$ ) [31], in both help-seeking and non-help-seeking SCD cases.

\section{METHODS}

The present study is part of the Norwegian multicenter study, Dementia Disease Initiation (DDI), a collaboration between all Norwegian health regions and University hospitals. Between January 2013 and January 2019, participants with self-reported cognitive decline and healthy controls were recruited. The DDI cohort comprises self-referred participants following advertisements in media, newspapers, or news bulletins, and patients referred from their general practitioners to local memory clinics. Healthy controls were included from spouses of patients with dementia/cognitive disorder, and from patients who completed lumbar puncture for orthopedic surgery. Classification of participants as either healthy controls, SCD, MCI, or dementia were performed according to published criteria [28, 32-34].

Inclusion criteria were a native language of Norwegian, Swedish, or Danish and age between 40 and 80 years. Participants with a medical history of brain trauma or brain disorder, including clinical stroke, dementia, severe psychiatric disorder, severe somatic disease that might influence cognitive functions, or intellectual disability or other developmental disorders were excluded. All participants were examined with a case report form developed for DDI. The case report form is administrated as a structured interview and includes a standardized assessment protocol for cognitive impairment and SCD (see below), medical history from participant and informant, physical 
and neurological examinations as well as the 15-item version of the GDS [31]. All participants underwent cognitive examination comprising the Mini-Mental State Examination (MMSE-NR) [35], non-verbal cognitive screening (The clock drawing test) [36], verbal memory (CERAD word list) [37], visuoperceptual ability (VOSP silhouettes) [38], psychomotor speed and executive functions (Trail making (TMT) A and B) [39], and word fluency (COWAT) [40]. For further description of the DDI cohort and methods, see Fladby et al. (2017) [20].

\section{Classification of SCD and cognitively normal healthy controls}

Classification of subjects as either SCD or cognitively normal healthy controls was performed as part of a structured interview with standardized questions, the DDI case report form. It includes a broad description of participants' symptoms and experience of subjective cognitive decline according to the suggested framework by the working group of SCDI. It considers onset of decline, cognitive domain, patient concerns and worries, if feeling of being worse compared to age-matched peers is present, and when available, informant confirmation of decline. Participants recruited from other sources than the memory clinics were asked if they had previously sought medical help due to SCD. Published norms (adjusted for age, sex, and educational effects) for the different tests were used to classify performance as normal or abnormal [38, 41, 42]. We applied a threshold of GDS-15 total score $\geq 6$ [31] for symptom of depression [31]. Cognitive performance was deemed normal if the participant obtained normative scores above $\mathrm{T}=35(\geq 1.5 \mathrm{SD})$ on either CERAD word list (delayed recall), VOSP silhouettes, TMTB, or COWAT. Participants with normal cognitive performance on standardized cognitive tests in combination with subjective decline in any cognitive domain were classified as SCD according to the SCD-I framework, which requires self-experienced cognitive decline unrelated to an acute event in any cognitive domain, normal functions of daily living (ADL-function), and performance within the normal range on standardized cognitive tests [28]. In contrast, cases classified as healthy controls had not experienced cognitive decline. For the purpose of this study, SCD participants were further classified as medical help-seekers (HS, $n=67$ ) or non-help-seekers (NHS, $n=44)$. Participants recruited from GP referral were automatically classified as HS ( $n=46 / 67,69 \%)$. In addition, participants recruited from advertisement who answered yes to having a prior history of seeking help for SCD were also classified as HS ( $n=21 / 67$, $31 \%)$. Participants recruited from advertisement who had not sought help for SCD were classified as NHS $(n=44)$.

\section{Participants}

The DDI cohort comprises cases classified as healthy controls, SCD, MCI, or dementia $(n=658)$. For the present study, only cognitively normal healthy controls and SCD cases with available CSF AD biomarkers from the DDI cohort $(n=199)$ were included. Our sample comprised cognitively normal healthy controls $(n=88)$, SCD-HS $(n=67)$, and SCD-NHS $(n=44)$. Informant confirmation of SCD was only available for a small subset of SCD cases $(n=39 / 111,35 \%)$, thus no statistical analyses were performed using this variable. However, type of SCD complaint (memory, language, orientation, or attention/executive functions) was included in our between-group analyses. An outline of the participant inclusion process is depicted in Fig. 1. For description of group demographics, see Table 1.

\section{CSF collection and handling}

Following DDI procedures as described previously [20], lumbar puncture was performed before noon, CSF was collected in polypropylene tubes (Thermo Nunc) and centrifuged within $4 \mathrm{~h}$ at $2000 \mathrm{~g}$ for $10 \mathrm{~min}$ at room temperature. The supernatant was transferred to new tubes and frozen at $-80^{\circ} \mathrm{C}$ prior to analysis. All CSF samples were analyzed at the Department of Interdisciplinary Laboratory Medicine and Medical Biochemistry at Akershus University Hospital, and samples from other DDI sites were frozen before shipment to the laboratory. Handling and analysis followed the BIOMARKAPD SOPs [43]. Analyses were performed consecutively as part of routine work-up, as described previously $[20,44]$, and showed an optimal cut-off at CSF $\mathrm{A} \beta_{1-42} \leq 708$ for amyloid plaque pathology as compared to a PET [18F]-flutemetamol uptake study [44].

\section{Protein biomarker measurements}

Commercial enzyme-linked immunosorbent assays based on monoclonal antibodies were used to measure CSF levels of the following protein biomarkers: $A \beta_{1-42}, t$-tau, and p-tau were deter- 


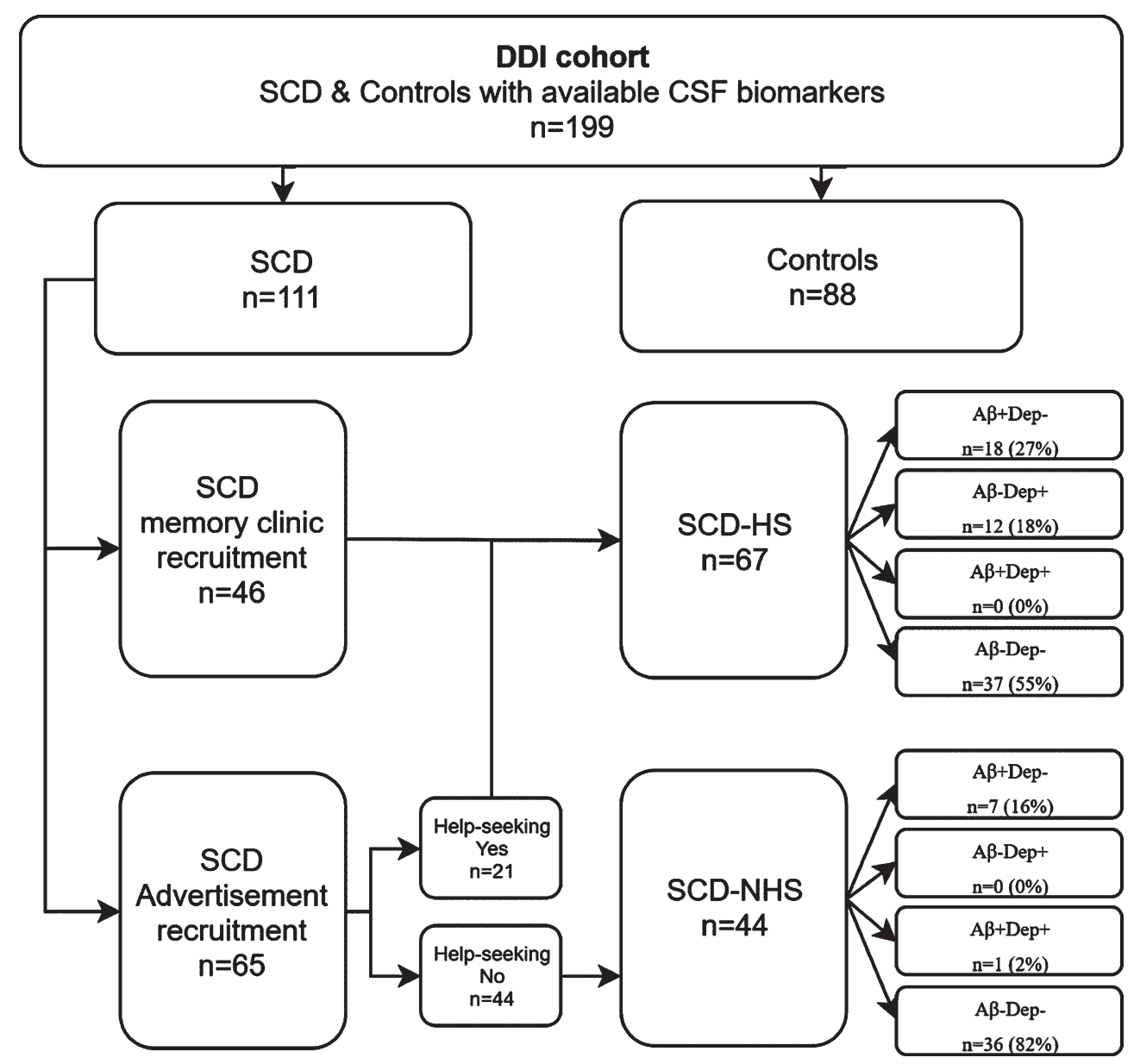

Fig. 1. A total of $n=199$ subjective cognitive decline (SCD) and controls from the Dementia Disease Initiation (DDI) cohort comprising $n=88$ cognitively healthy controls, $n=67$ SCD with a history of medical help seeking (SCD-HS) and $n=44$ SCD non-help-seekers (SCD-NHS) were included.

mined using Innotest A $\beta$ (1-42), Innotest h-Tau Ag, and Innotest Phospho-Tau (181P) (Fujirebio, Ghent, Belgium), respectively.

\section{Statistical analysis}

Examination of QQ-plots, histograms, and the Shapiro-Wilks test of normality were used to assess normality. For variables with normal distributions, assessment of between group differences in CSF biomarker levels, cognition, age, and years of education were performed using one-way ANOVAs with planned comparisons. Kruskal-Wallis test with Dunn's non-parametric pairwise post-hoc test was used to assess group differences in variables with nonnormal distributions (CSF A $\beta_{1-42}$, CSF t-tau, CSF $\mathrm{t}$-tau, and MMSE). The dichotomous variable "sex" and between-group distributions of SCD complaint type were assessed using a chi square test. For statistically significant between-group differences using one-way ANOVAs or Kruskal-Wallis tests, effect sizes (eta squared, $\eta^{2}$ ) are reported. Groups were compared in the following manner: First, we compared healthy controls to both the SCD-HS and SCD-NHS groups. Then, SCD-HS group was compared to SCD-NHS group. Lastly, we compared the distribution of symptoms of depression with or without the presence of amyloid plaques between the SCD-HS and SCD-NHS groups using a chi square test as well as observed numbers and percentages. This yielded four groups comprising cases with amyloid plaques without symptoms of depression (A $\beta+$ Dep-), symptoms of depression without amyloid plaques $(\mathrm{A} \beta-\mathrm{Dep}+)$, amyloid plaques and symptoms of depression (A $\beta+\mathrm{Dep}+)$, and lastly, cases with neither amyloid plaques nor symptoms of 
Table 1

Between-group comparisons of CSF biomarkers, cognitive performance, demographics and depressive symptoms

\begin{tabular}{|c|c|c|c|c|c|c|c|}
\hline \multirow[t]{2}{*}{ Variable } & \multicolumn{3}{|c|}{ Groups } & \multirow[t]{2}{*}{$F / \chi^{2} / \eta^{2} /(p)$} & \multicolumn{3}{|c|}{ ANOVA planned contrasts (p) } \\
\hline & $\begin{array}{c}\text { 1. Controls } \\
n=88\end{array}$ & $\begin{array}{c}\text { 2. SCD-HS } \\
n=67\end{array}$ & $\begin{array}{c}\text { 3. SCD-NHS } \\
n=44\end{array}$ & & 1 versus 2 & 1 versus 3 & 2 versus 3 \\
\hline \multicolumn{8}{|l|}{ Age } \\
\hline Mean (SD) & $61.4(9.4)$ & $60.8(8.3)$ & $64.2(9.9)$ & $F=1.9,($ n.s $)$ & $n . s$ & $n . s$ & n.s \\
\hline \multicolumn{8}{|l|}{ Female } \\
\hline $\mathrm{n}(\%)$ & $48(55 \%)$ & $33(49 \%)$ & $17(39 \%)$ & $\chi^{2}=2.8,(\mathrm{n} . \mathrm{s})$ & $*$ & $*$ & $*$ \\
\hline \multicolumn{8}{|l|}{ Years of education } \\
\hline Mean (SD) & $14.0(3.3)$ & $13.6(3.3)$ & $13.5(3.3)$ & $F=0.6,(\mathrm{n} . \mathrm{s})$ & * & * & * \\
\hline \multicolumn{8}{|l|}{ GDS 15} \\
\hline Mean (SD) & $0.7(1.1)$ & $3.9(3.0)$ & $1.7(2.0)$ & $F=43.6, \eta^{2}=0.31,(<\mathbf{0 . 0 0 0 1})$ & $<0.0001$ & $<0.05$ & $<0.0001$ \\
\hline \multicolumn{8}{|l|}{ MMSE } \\
\hline Median (IQR) & $30(1)$ & $29(1)$ & $30(2)$ & $\chi^{2}=0.3,(\mathrm{n} . \mathrm{s})$ & $*$ & $*$ & $*$ \\
\hline \multicolumn{8}{|l|}{ CERAD Learning T-score } \\
\hline Mean (SD) & $52.9(9.8)$ & $47.0(9.6)$ & $53.4(9.0)$ & $F=8.8, \eta^{2}=0.08,(<\mathbf{0 . 0 0 0 1})$ & $<0.0001$ & $n . s$ & $<0.001$ \\
\hline \multicolumn{8}{|l|}{ CERAD Recall T-score } \\
\hline Mean (SD) & $52.8(7.8)$ & $47.6(8.9)$ & $52.8(9.0)$ & $F=8.3, \eta^{2}=0.08,(<\mathbf{0 . 0 0 1})$ & $<0.0001$ & $n . s$ & $<0.01$ \\
\hline \multicolumn{8}{|l|}{ TMT-A T-score } \\
\hline Mean (SD) & $49.4(9.0)$ & $49.9(8.4)$ & $47.5(9.7)$ & $F=1.1,(\mathrm{n} . \mathrm{s})$ & * & * & * \\
\hline \multicolumn{8}{|l|}{ TMT-B T-score } \\
\hline Mean (SD) & $52.2(7.6)$ & $50.5(8.7)$ & $50.8(7.8)$ & $F=1.0,(\mathrm{n} . \mathrm{s})$ & * & * & * \\
\hline \multicolumn{8}{|l|}{ COWAT T-score } \\
\hline Mean (SD) & $51.7(8.2)$ & $51.8(9.3)$ & $51.9(8.9)$ & $F=1.0,(\mathrm{n} . \mathrm{s})$ & * & * & * \\
\hline \multicolumn{8}{|l|}{ VOSP silhouettes } \\
\hline Mean (SD) & $52.6(9.0)$ & $51.1(11.0)$ & $54.9(9.7)$ & $F=0.2,(\mathrm{n} . \mathrm{s})$ & * & * & * \\
\hline \multicolumn{8}{|l|}{ CSF A $\beta 1-42$} \\
\hline Mean (SD) & $1055(230)$ & $932(310)$ & $1022(296)$ & $F=3.9, \eta^{2}=0.04,(<\mathbf{0 . 0 5})$ & $<0.01$ & $n . s$ & $n . s$ \\
\hline \multicolumn{8}{|l|}{ CSF t-tau } \\
\hline Mean (SD) & $324(152)$ & $335(210)$ & $364(181)$ & $F=0.7,(\mathrm{n} . \mathrm{s})$ & $n . s$ & $n . s$ & $n . s$ \\
\hline \multicolumn{8}{|l|}{ CSF p-tau } \\
\hline Mean (SD) & $53(19)$ & $57(30)$ & $59(23)$ & $F=1.0,($ n.s $)$ & $n . s$ & $n . s$ & $n . s$ \\
\hline SCD Memory $n(\%)$ & & $53(84 \%)$ & $32(80 \%)$ & $\chi^{2}=0.6,(\mathrm{n} . \mathrm{s})$ & * & * & * \\
\hline SCD Executive functions $n(\%)$ & & $3(5 \%)$ & $3(7 \%)$ & $\chi^{2}=0.3,(\mathrm{n} . \mathrm{s})$ & * & * & * \\
\hline SCD Language $n(\%)$ & & $5(8 \%)$ & $10(13 \%)$ & $\chi^{2}=0.5,(\mathrm{n} . \mathrm{s})$ & * & * & * \\
\hline SCD Orientation $n(\%)$ & & $2(3 \%)$ & $0(0 \%)$ & $\chi^{2}=1.3,(\mathrm{n} . \mathrm{s})$ & $*$ & $*$ & $*$ \\
\hline
\end{tabular}

n, sample size; n.s., non-significant results; *No contrasts/post hoc tests performed; F, F-statistic; $\chi^{2}$, chi-square or Kruskal-Wallis statistic; $\eta^{2}$, eta-squared, $\mathrm{p}, p$-value.

depression (A $\beta$-Dep-). All analyses were performed in the Statistical Package for Social Sciences (SPSS) version 25 .

\section{Ethics}

The Regional Medical Research Ethics committee approved the study. All participants gave their written informed consent before taking part in the study. All further study conduct was in line with the guidelines provided by the Helsinki declaration of 1964; revised 2013 and the Norwegian Health and Research act.

\section{RESULTS}

Group comparisons of cognitive performance and demographics

Between-group comparisons of cognitive variables and demographics are shown in Table 1.
While the SCD-NHS group had similar cognitive scores as the healthy controls, SCD-HS had significantly lower scores on both CERAD learning and delayed memory recall as compared to both controls $(p<0.0001 ; p<0.0001)$ and SCD-NHS group $(p<0.0001 ; p<0.001)$. There was no significant difference in type of SCD cognitive complaint, age, years of education, or sex distribution between the groups.

\section{Group comparisons of GDS-15 depressive symptoms}

Between-group comparisons of GDS-15 are shown in Table 1.

Both SCD-HS $(p<0001)$ and SCD-NHS $(<0.05)$ groups reported higher levels of depressive symptoms as compared to controls. However, SCD-HS group reported more depressive symptoms than the SCDNHS group $(p<0.0001)$. 


\section{Between-group CSF AD biomarkers comparisons}

Between-group comparisons of CSF variables are shown in Table 1.

While SCD-NHS had similar CSF A $\beta_{1-42}$ levels as compared to controls, SCD-HS had lower CSF $\mathrm{A} \beta_{1-42}$ as compared to both SCD-NHS $(p<0.05)$ and controls $(p<0.001)$.

We found no between-group differences in CSF $\mathrm{t}$-tau or p-tau levels.

\section{Within-group distributions of amyloid plaques and symptoms of depression}

There were higher rates of $\mathrm{A} \beta+\mathrm{Dep}$ - cases $(n=18$, $27 \%$ ) within the SCD-HS group as compared to the SCD-NHS group (A $\beta+$ Dep-, $n=7,16 \%, p<0.0001$ ). Moreover, we found higher rates of $\mathrm{A} \beta$-Dep+ cases $(n=12,18 \%, p<0.0001)$ in the SCD-HS group as compared to no cases within the SCD-NHS group. No $A \beta+D e p+$ cases were found in the SCD-HS group and only one case within the SCD-NHS group was $\mathrm{A} \beta+$ Dep+ (see Table 2).

\section{Within-group differences in cognitive performance and demographics}

In light of the results shown in the previous section, we performed Kruskal-Wallis tests with Bonferroni adjusted Dunn's pairwise comparisons to investigate potential differences in cognitive performance and demographics between SCD help-seekers with either amyloid plaques or symptoms of depression and cases with neither symptoms of depression nor amyloid plaques (see Table 3). While helpseekers with symptoms of depression were younger $(\mathrm{M}=55.8, \mathrm{SD}=8.4)$ compared to cases with amyloid plaques $(\mathrm{M}=64.5, \mathrm{SD}=8.3, p<0.05)$, no significant between-group differences in cognitive performance or demographics were found.

Table 2

Frequencies of amyloid plaques and symptoms of depression in SCD-HS and SCD-NHS

\begin{tabular}{lccc}
\hline Groups & $\begin{array}{c}\text { SCD-HS } \\
\mathrm{n}(\%)\end{array}$ & $\begin{array}{c}\text { SCD-NHS } \\
\mathrm{n}(\%)\end{array}$ & $\chi^{2}(p)$ \\
\hline A $\beta$ - Dep- & $37(55 \%)$ & $36(82 \%)$ & $\chi^{2}=73.0, \mathbf{p}<\mathbf{0 . 0 0 0 1}$ \\
A $\beta$ + Dep- & $18(27 \%)$ & $7(16 \%)$ & $\chi^{2}=25.0, \mathbf{p}<\mathbf{0 . 0 0 0 1}$ \\
A $\beta$ - Dep+ & $12(18 \%)$ & $0(0 \%)$ & $*$ \\
A $\beta$ + Dep+ & $0(0 \%)$ & $1(2 \%)$ & $*$ \\
\hline
\end{tabular}

p, $p$-value; $n$, sample size; $\chi^{2}$, chi-square test; $A \beta+/-$, presence or absence of amyloid plaque pathology (CSF $\left.A \beta_{1-42} \geq 708\right)$; Dep+/-, presence or absence of symptoms of depression (GDS $\geq 6$ ). *No statistical tests performed.

\section{DISCUSSION}

The main finding of this study was that SCD cases with self-reported history of medical help-seeking had lower levels of CSF A $\beta_{1-42}$, weaker performance on the CERAD word list memory test, and increased levels of depressive symptoms compared to both SCD non-help-seekers and controls. However, additional analyses revealed that the SCD help-seeker group comprised three subgroups: 1) subjects with symptoms of depression, 2) subjects with amyloid plaques, and 3) subjects with neither amyloid plaques nor symptoms of depression. Of note, none of the SCD help-seekers had both amyloid plaques and symptoms of depression. Interestingly, all three subgroups of SCD help-seekers showed equal memory performance, regardless of amyloid status or symptoms of depression.

While many studies have found recruitment source differences in both $\mathrm{AD}$ biomarker prevalence and cognitive performance in MCI [21, 24, 25], studies on SCD have been inconsistent [22, 24, 26, 27]. A recent meta-analysis found no difference in the risk of progression of SCD patients recruited by different means [4]. This is in line with a previous report from our group, showing no significant differences in cognitive performance or demographics between memory-clinic referred and self-referred SCD cases from the community [24]. Inconsistencies between studies may partly be due to help-seeking SCD patients not being referred for extensive assessment at memory clinics by their GP. These individuals may subsequently volunteer for research participation.

Several studies have shown that SCD cases recruited through memory clinics show increased rates of pathological $\mathrm{AD}$ biomarkers [20, 26, 27]. In the present study, we found lower CSF $A \beta_{1-42}$ in the SCD-HS group as compared to both SCD-NHS and controls. Additional analyses confirmed that the SCD-HS group had a higher rate of amyloid plaques $(n=18,27 \%)$ compared to the SCD-NHS group $(n=8,18 \%)$. The majority of these cases $(n=46$, $69 \%$ ) were indeed recruited from memory clinics, which supports the idea of a recruitment bias when including at-risk cases from memory clinics $[23,26$, 27]. Moreover, we also found subtle deficits in memory performance in the SCD-HS group compared to both SCD-NHS and controls. This is in contrast to our previous study where no differences in cognitive performance between memory-clinic referred and self-referred SCD cases from the community 
Table 3

Comparisons of demographics and cognitive performance between SCD help-seekers with either amyloid plaques or symptoms of depression and cases with neither amyloid plaques nor symptoms of depression

\begin{tabular}{|c|c|c|c|c|c|c|c|}
\hline \multirow[t]{2}{*}{ Variable } & \multicolumn{3}{|c|}{ Groups } & \multirow[t]{2}{*}{$\chi^{2} / \eta^{2} /(p)$} & \multicolumn{3}{|c|}{$\begin{array}{l}\text { Bonferroni adjusted Dunn's } \\
\text { pairwise comparisons }(p)\end{array}$} \\
\hline & $\begin{array}{c}\text { 1. SCD-HS } \\
\text { A } \beta \text {-Dep- } \\
n=37\end{array}$ & $\begin{array}{c}\text { 2. SCD-HS } \\
\text { A } \beta \text { +Dep- } \\
n=18\end{array}$ & $\begin{array}{c}\text { 3. SCD-HS } \\
\text { A } \beta \text {-Dep+ } \\
n=12\end{array}$ & & 1 versus 2 & 1 versus 3 & 2 versus 3 \\
\hline \multicolumn{8}{|l|}{ Age } \\
\hline Mean (SD) & $60.7(7.6)$ & $64.5(8.3)$ & $55.8(8.4)$ & $\chi^{2}=7.7, \eta^{2}=0.09,(<\mathbf{0 . 0 5})$ & n.s & $n . s$ & $<0.05$ \\
\hline \multicolumn{8}{|l|}{ Female } \\
\hline $\begin{array}{l}\text { Years of educatiol } \\
\text { Mean (SD) }\end{array}$ & $13.8(3.5)$ & $13.5(3.2)$ & $12.8(2.9)$ & $\chi^{2}=0.5,(\mathrm{n} . \mathrm{s})$ & * & $*$ & $*$ \\
\hline \multicolumn{8}{|l|}{ MMSE } \\
\hline $\begin{array}{l}\text { Median (IQR) } \\
\text { CERAD Learning }\end{array}$ & $29(2)$ & $30(2)$ & $29(3)$ & $\chi^{2}=0.4,(\mathrm{n} . \mathrm{s})$ & $*$ & $*$ & $*$ \\
\hline $\begin{array}{l}\text { Mean (SD) } \\
\text { CERAD Recall T }\end{array}$ & $47.4(10.2)$ & $48.8(8.7)$ & $43.2(8.6)$ & $\chi^{2}=3.4,(\mathrm{n} . \mathrm{s})$ & $*$ & $*$ & * \\
\hline $\begin{array}{l}\text { Mean (SD) } \\
\text { TMT-A T-score }\end{array}$ & $47.8(9.2)$ & $47.4(9.3)$ & $47.1(7.5)$ & $\chi^{2}=0.9,($ n.s $)$ & $*$ & $*$ & $*$ \\
\hline $\begin{array}{l}\text { Mean (SD) } \\
\text { TMT-B T-score }\end{array}$ & $48.9(8.3)$ & $58.9(8.8)$ & $48.5(7.5)$ & $\chi^{2}=2.4,($ n.s $)$ & * & $*$ & $*$ \\
\hline $\begin{array}{c}\text { Mean (SD) } \\
\text { COWAT T-score }\end{array}$ & $51.9(9.4)$ & $50.7(6.7)$ & $45.9(7.8)$ & $\chi^{2}=3.3$, (n.s) & $*$ & * & $*$ \\
\hline $\begin{array}{c}\text { Mean (SD) } \\
\text { VOSP silhouettes }\end{array}$ & $52.4(8.8)$ & $51.2(10.1)$ & $51.0(10.5)$ & $\chi^{2}=0.2,(\mathrm{n} . \mathrm{s})$ & $*$ & $*$ & $*$ \\
\hline Mean (SD) & $51.5(13.0)$ & $51.4(8.1)$ & $59.8(9.2)$ & $\chi^{2}=0.9,(\mathrm{n} . \mathrm{s})$ & $*$ & $*$ & $*$ \\
\hline
\end{tabular}

$\mathrm{A} \beta+/-$, presence or absence of amyloid plaque pathology $\left(\mathrm{CSF} A \beta_{1-42} \leq 708\right)$; Dep+/-, presence or absence of symptoms of depression (GDS $\geq 6$ ); n, sample size; n.s., non-significant results; *No contrasts/post hoc tests performed; $\chi^{2}$, chi-square or Kruskal-Wallis statistic; $\eta^{2}$, eta-squared, $\mathrm{p}, p$-value. Pairwise comparisons are adjusted for multiple comparisons using Bonferroni correction of the $p$-values.

could be demonstrated [24]. These findings suggest that help seeking status, not memory clinic recruitment per se, may be a risk factor for early amyloid deposition which could tie in with the subtle deficits in memory performance observed in the SCD-HS group. Moreover, we did not find differences in CSF biomarkers or cognitive performance between SCD NHS and controls, suggesting that the SCD-NHS group has lower risk and may reflect higher rates of benign SCD [16-18]. No differences between groups were found in levels of CSF t-tau or p-tau. This is perhaps not surprising, as increased levels of t-tau and p-tau are associated with substantial formation of neurofibrillary tangles and neuronal loss which may happen downstream from amyloid deposition and herald the onset of clinical cognitive impairment at later stages [45]. It has been suggested that weakening of memory performance is at first related to $A \beta_{1-42}$ levels, and progressive loss of neurons and the formation of neurofibrillary tangles is associated with disease severity and progression to dementia [46]. Indeed, several studies have suggested that the presence of amyloid pathology in SCD is the strongest predictor of future cognitive decline [11-13].

Both SCD-HS and SCD-NHS groups had increased levels of depressive symptoms compared to controls. The increase in symptoms may reflect the psychological strain of experiencing cognitive difficulties regardless of brain pathology. However, levels of depressive symptoms as measured by the GDS15 were significantly higher in SCD-HS. Additional analyses revealed that this group indeed comprised a high rate of individuals with above threshold (GDS-15 $\geq 6$ ) symptoms of depression $(n=12,18 \%)$. However, none of these individuals harbored amyloid pathology, suggesting that symptoms of depression may not be strongly associated with AD in its preclinical phases and also that symptoms of depression in these cases are not due to the strain of experiencing incipient AD.

While memory performance has shown to predict later cognitive decline and future dementia onset [47, 48], deficits in cognitive performance is also a core feature in clinical depression [49]. Cognitive deficits in depression have been reported within a number 
of cognitive domains including executive functioning, attention, learning, memory, and psychomotor speed [50-52]. Interestingly, while we found poorer memory function in help-seeking SCD cases as compared to non-help-seekers, additional analyses could not distinguish SCD help-seekers with symptoms of depression from help-seekers with amyloid plaques with regard to cognitive performance in neither memory domains nor other cognitive domains. However, there are conflicting results regarding which domains of cognition are selectively affected in clinical depression [53-57].

As most SCD cases are benign, or not caused by degenerative brain disease [17], it has been suggested that SCD may be associated with depression, rather than preclinical $\mathrm{AD}[58,59]$. While it has been reported that presentation of SCD may correlate with depression rather than objective cognitive decline $[60,61]$, the link between SCD and depressive symptoms has not been universally supported [62, 63].

Nonetheless, it has been reported that prior history of depression is associated with increased risk of developing AD [64]. Indeed, clinical depression is associated with $\mathrm{AD}$ later in the disease trajectory $[65,66]$, and an association between amyloid pathology and late-life depression has been found in several studies [67-70]. However, recent studies have demonstrated that this may not be the case in the preclinical phase of AD. Perin et al. [71] showed that incidence of clinical depression, as determined by the GDS-15, was not increased in cognitively normal individuals with amyloid plaques. Similarly, Donovan et al. [72] showed that an increased level of depressive symptoms was not associated with the presence of amyloid plaques in cognitively healthy cases. These results tie in with our findings, as we did not find an association between amyloid plaques and symptoms of depression in SCD cases. However, this does not dismiss a relationship between AD pathology and clinical depression as the disease progresses.

Although clinical depression and preclinical AD may not be linked, several studies have suggested that subthreshold symptoms of depression and anxiety may be manifestations of preclinical AD [73-75]. Subthreshold levels of depression could be related to worry due to self-perceived reduction in cognition, rather than reflecting clinical depression, in that awareness of SCD causes depressive symptoms which explains increases in distress [76]. Several studies have shown that worried individuals with
SCD have an increased risk of developing objective cognitive decline $[6,28,29,77]$. However, Chen, et al. [62] recently showed that individuals with amyloid plaques, self-reported memory difficulties or memory concerns and not depression or anxiety, were associated with self-awareness of actual worsening in memory function [62]. In our sample, memory was the most frequent SCD complaint, regardless of help-seeking status. This ties in with findings showing that worry is associated with an increased risk of dementia rather than the mere presence of memory complaints [77]. Taken together, this suggests that specific concerns regarding cognition, not subthreshold levels of depression or anxiety, may confer increased risk of clinical progression. These reports are in accordance with our findings showing that help-seeking due to SCD with amyloid plaques may reflect worry or concerns due to a subtle deficit in memory function which is unrelated to symptoms of depression.

We also identified individuals with neither amyloid plaques nor symptoms of depression among the help-seeking group with subtle memory deficits, perhaps reflecting a different type of pathology such as preclinical Lewy body dementia [78], earlier stages of preclinical AD not yet identified using conventional CSF biomarker cut-offs for amyloid pathology (i.e., pre-plaque amyloid dysmetabolism) or perhaps comprising of worried participants with normal age-related memory decline without the presence of neurodegenerative brain disease [79]. This finding also points to a central limitation of our study, which is confined to a cross sectional design and information of progression is therefore lacking. A longitudinal design is needed to assess whether helpseeking SCD cases with amyloid plaques progress to AD-type MCI or dementia, and if participants without amyloid plaques with, or without symptoms of depression will regress or progress with regards to depressive symptoms, SCD, and cognitive performance. Moreover, we did not include information about whether help-seeking was caused by subjective worry due to SCD, or if individuals sought help for other reasons, i.e., having a family history of $\mathrm{AD}$, or informant concern. Unfortunately, due to a lack of available informant reports, this data was not included in our analysis. It has been shown that informant concern may be a better predictor than selfconcern of objective cognitive decline [80], and it has been argued that many patients may not express their concern to their GPs [81]. Consequently, non-helpseeking SCD also includes cases with AD pathology, 
albeit with different reasons for not seeking medical help.

\section{Conclusions}

Our findings shed light on the relationship between depressive symptoms and preclinical $\mathrm{AD}$, which may inform researchers including at-risk cases for interventions studies, as well as GPs seeing cognitively healthy, but worried patients with SCD. While our results support the idea that individuals with SCD seeking help may be at higher risk of $\mathrm{AD}, \mathrm{SCD}$ help-seekers also included younger individuals with symptoms of depression without amyloid plaques as well as individuals with neither symptoms of depression nor amyloid plaques. These subgroups could not be distinguished based on performance on neuropsychological tests, and longitudinal studies are needed to ascertain the clinical progression of SCD helpseekers with regards to the presence or absence of symptoms of depression and amyloid plaques.

\section{ACKNOWLEDGMENTS}

This project was funded by Norwegian Research Council, NASATS (Dementia Disease Initiation) and the JPND (APGeM) and funding from the regional health authorities (Helse Sør-Øst and Helse Nord). We would like to thank Svein Ivar Bekkelund, Kjell-Arne Arntzen, Kai Müller, Torgil Riise Vangberg, Claus Albretsen, Elisabeth Gundersen, Mari Thoresen Løkholm, Ida Harviken, Line Sæther, Erna Utnes, Marianne Wettergren, Berglind Gisladottir, Marit Knapstad, Reidun Meling, and Synnøve Bremer Skarpenes for clinical examinations and essential help with the project.

Authors' disclosures available online (https:// www.j-alz.com/manuscript-disclosures/19-0712r2).

\section{REFERENCES}

[1] Perrin RJ, Fagan AM, Holtzman DM (2009) Multimodal techniques for diagnosis and prognosis of Alzheimer's disease. Nature 461, 916-922.

[2] Buchhave P, Minthon L, Zetterberg H, Wallin AK, Blennow K, Hansson O (2012) Cerebrospinal fluid levels of betaamyloid 1-42, but not of tau, are fully changed already 5 to 10 years before the onset of Alzheimer dementia. Arch Gen Psychiatry 69, 98-106.

[3] Blennow K (2011) Paving the way for Alzheimer disease drug development. Nat Rev Neurol 7, 65.

[4] Mitchell AJ, Beaumont H, Ferguson D, Yadegarfar M, Stubbs B (2014) Risk of dementia and mild cognitive impairment in older people with subjective memory complaints: Meta-analysis. Acta Psychiatr Scand 130, 439-451.

[5] Mendonça MD, Alves L, Bugalho P (2016) From subjective cognitive complaints to dementia. Am J Alzheimers Dis Other Demen 31, 105-114.

[6] Reisberg B, Gauthier S (2008) Current evidence for subjective cognitive impairment (SCI) as the pre-mild cognitive impairment (MCI) stage of subsequently manifest Alzheimer's disease. Int Psychogeriatr 20, 1-16.

[7] Sperling RA, Aisen PS, Beckett LA, Bennett DA, Craft S, Fagan AM, Iwatsubo T, Jack CR, Jr., Kaye J, Montine TJ, Park DC, Reiman EM, Rowe CC, Siemers E, Stern Y, Yaffe K, Carrillo MC, Thies B, Morrison-Bogorad M, Wagster MV, Phelps CH (2011) Toward defining the preclinical stages of Alzheimer's disease: Recommendations from the National Institute on Aging-Alzheimer's Association workgroups on diagnostic guidelines for Alzheimer's disease. Alzheimers Dement 7, 280-292.

[8] Jessen F (2014) Subjective and objective cognitive decline at the pre-dementia stage of Alzheimer's disease. Eur Arch Psychiatry Clin Neurosci 264, 3-7.

[9] Geerlings MI1, Jonker C, Bouter LM, Adèr HJ, Schmand B (1999) Association between memory complaints and incident Alzheimer's disease in elderly people with normal baseline cognition. Am J Psychiatry 156, 531-537.

[10] Rönnlund M, Sundström A, Adolfsson R, Nilsson L-G (2015) Self-reported memory failures: Associations with future dementia in a population-based study with long-term follow-up. J Am Geriatr Soc 63, 1766-1773.

[11] Vogel JW, Varga Dolezalova M, La Joie R, Marks SM, Schwimmer HD, Landau SM, Jagust WJ (2017) Subjective cognitive decline and beta-amyloid burden predict cognitive change in healthy elderly. Neurology 89, 2002-2009.

[12] van Harten AC, Visser PJ, Pijnenburg YA, Teunissen CE, Blankenstein MA, Scheltens P, van der Flier WM (2013) Cerebrospinal fluid Abeta42 is the best predictor of clinical progression in patients with subjective complaints. Alzheimers Dement 9, 481-487.

[13] Sierra-Rio A, Balasa M, Olives J, Antonell A, Iranzo A, Castellvi M, Bosch B, Grau-Rivera O, Fernandez-Villullas G, Rami L, Llado A, Sanchez-Valle R, Molinuevo JL (2016) Cerebrospinal fluid biomarkers predict clinical evolution in patients with subjective cognitive decline and mild cognitive impairment. Neurodegener Dis 16, 69-76.

[14] Erk S, Spottke A, Meisen A, Wagner M, Walter H, Jessen F (2011) Evidence of neuronal compensation during episodic memory in subjective memory impairment. Arch Gen Psychiatry 68, 845-852.

[15] Eckerstrom M, Berg AI, Nordlund A, Rolstad S, Sacuiu S, Wallin A (2016) High prevalence of stress and low prevalence of Alzheimer disease CSF biomarkers in a clinical sample with subjective cognitive impairment. Dement Geriatr Cogn Dis 42, 93-105.

[16] Bassett SS, Folstein MF (1993) Memory complaint, memory performance, and psychiatric diagnosis: A community study. J Geriatr Psychiatry Neurol 6, 105-111.

[17] Hessen E, Eckerström M, Nordlund A, Selseth Almdahl I, Stålhammar J, Bjerke M, Eckerström C, Göthlin M, Fladby T, Reinvang I, Wallin A (2017) Subjective cognitive impairment is a predominantly benign condition in memory clinic patients followed for 6 years: The GothenburgOslo MCI Study. Dement Geriatr Cogn Dis Extra 7, $1-14$.

[18] Abdulrab K, Heun R (2008) Subjective memory impairment. A review of its definitions indicates the need for a 
comprehensive set of standardised and validated criteria. Eur Psychiatry 23, 321-330.

[19] Tepest R, Wang L, Csernansky JG, Neubert P, Heun R, Scheef L, Jessen F (2008) Hippocampal surface analysis in subjective memory impairment, mild cognitive impairment and Alzheimer's dementia. Dement Geriatr Cogn Disord 26, 323-329.

[20] Fladby T, Palhaugen L, Selnes P, Waterloo K, Brathen G, Hessen E, Almdahl IS, Arntzen KA, Auning E, Eliassen CF, Espenes R, Grambaite R, Grontvedt GR, Johansen KK, Johnsen SH, Kalheim LF, Kirsebom BE, Muller KI, Nakling AE, Rongve A, Sando SB, Siafarikas N, Stav AL, Tecelao S, Timon S, Bekkelund SI, Aarsland D (2017) Detecting at-risk Alzheimer's disease cases. J Alzheimers Dis 60, 97-105.

[21] Brodaty H, Mothakunnel A, de Vel-Palumbo M, Ames D, Ellis KA, Reppermund S, Kochan NA, Savage G, Trollor JN, Crawford J, Sachdev PS (2014) Influence of population versus convenience sampling on sample characteristics in studies of cognitive aging. Ann Epidemiol 24, 63-71.

[22] Perrotin A, La Joie R, de La Sayette V, Barre L, Mezenge F, Mutlu J, Guilloteau D, Egret S, Eustache F, Chetelat G (2017) Subjective cognitive decline in cognitively normal elders from the community or from a memory clinic: Differential affective and imaging correlates. Alzheimers Dement 13, 550-560.

[23] Snitz BE, Wang T, Cloonan YK, Jacobsen E, Chang CH, Hughes TF, Kamboh MI, Ganguli M (2018) Risk of progression from subjective cognitive decline to mild cognitive impairment: The role of study setting. Alzheimers Dement 14, 734-742.

[24] Kirsebom BE, Espenes R, Waterloo K, Hessen E, Johnsen SH, Brathen G, Aarsland D, Fladby T (2017) Screening for Alzheimer's disease: Cognitive impairment in self-referred and memory clinic-referred patients. J Alzheimers Dis $\mathbf{6 0}$, 1621-1631.

[25] Farias ST, Mungas D, Reed BR, Harvey D, DeCarli C (2009) Progression of mild cognitive impairment to dementia in clinic- vs community-based cohorts. Arch Neurol 66, 11511157.

[26] Chen Y, Denny KG, Harvey D, Farias ST, Mungas D, DeCarli C, Beckett L (2017) Progression from normal cognition to mild cognitive impairment in a diverse clinic-based and community-based elderly cohort. Alzheimers Dement 13, 399-405.

[27] Abdelnour C, Rodriguez-Gomez O, Alegret M, Valero S, Moreno-Grau S, Sanabria A, Hernandez I, RosendeRoca M, Vargas L, Mauleon A, Sanchez D, Espinosa A, Ortega G, Perez-Cordon A, Diego S, Gailhajanet A, Guitart M, Sotolongo-Grau O, Ruiz A, Tarraga L, Boada M (2017) Impact of recruitment methods in subjective cognitive decline. J Alzheimers Dis 57, 625-632.

[28] Jessen F, Amariglio RE, van Boxtel M, Breteler M, Ceccaldi M, Chetelat G, Dubois B, Dufouil C, Ellis KA, van der Flier WM, Glodzik L, van Harten AC, de Leon MJ, McHugh P, Mielke MM, Molinuevo JL, Mosconi L, Osorio RS, Perrotin A, Petersen RC, Rabin LA, Rami L, Reisberg B, Rentz DM, Sachdev PS, de la Sayette V, Saykin AJ, Scheltens P, Shulman MB, Slavin MJ, Sperling RA, Stewart R, Uspenskaya O, Vellas B, Visser PJ, Wagner M (2014) A conceptual framework for research on subjective cognitive decline in preclinical Alzheimer's disease. Alzheimers Dement 10, 844-852.

[29] Rabin LA, Wang C, Katz MJ, Derby CA, Buschke H, Lipton RB (2012) Predicting Alzheimer's disease: Neuropsycho- logical tests, self-reports, and informant reports of cognitive difficulties. J Am Geriatr Soc 60, 1128-1134.

[30] Jenkins A, Tales A, Tree J, Bayer A (2015) Are we ready? The construct of subjective cognitive impairment and its utilization in clinical practice: A preliminary UK-based service evaluation. J Alzheimers Dis 48 Suppl 1, S25-31.

[31] Mitchell AJ, Bird V, Rizzo M, Meader N (2010) Diagnostic validity and added value of the geriatric depression scale for depression in primary care: A meta-analysis of GDS30 and GDS15. J Affect Disord 125, 10-17.

[32] Albert MS, DeKosky ST, Dickson D, Dubois B, Feldman HH, Fox NC, Gamst A, Holtzman DM, Jagust WJ, Petersen RC, Snyder PJ, Carrillo MC, Thies B, Phelps CH (2011) The diagnosis of mild cognitive impairment due to Alzheimer's disease: Recommendations from the National Institute on Aging-Alzheimer's Association workgroups on diagnostic guidelines for Alzheimer's disease. Alzheimers Dement 7, 270-279.

[33] Jack CR, Jr., Bennett DA, Blennow K, Carrillo MC, Dunn B, Haeberlein SB, Holtzman DM, Jagust W, Jessen F, Karlawish J, Liu E, Molinuevo JL, Montine T, Phelps C, Rankin KP, Rowe CC, Scheltens P, Siemers E, Snyder HM, Sperling R (2018) NIA-AA Research Framework: Toward a biological definition of Alzheimer's disease. Alzheimers Dement 14, 535-562.

[34] McKhann GM, Knopman DS, Chertkow H, Hyman BT, Jack CR, Kawas CH, Klunk WE, Koroshetz WJ, Manly JJ, Mayeux R, Mohs RC, Morris JC, Rossor MN, Scheltens P, Carrillo MC, Thies B, Weintraub S, Phelps $\mathrm{CH}$ (2011) The diagnosis of dementia due to Alzheimer's disease: Recommendations from the National Institute on Aging-Alzheimer's Association workgroups on diagnostic guidelines for Alzheimer's disease. Alzheimers Dement 7, 263-269.

[35] Folstein MF, Folstein SE, McHugh PR (1975) "Mini-mental state". A practical method for grading the cognitive state of patients for the clinician. J Psychiatr Res 12, 189-198.

[36] Shulman KI (2000) Clock-drawing: Is it the ideal cognitive screening test? Int J Geriatr Psychiatry 15, 548-561.

[37] Fillenbaum GG, van Belle G, Morris JC, Mohs RC, Mirra SS, Davis PC, Tariot PN, Silverman JM, Clark CM, WelshBohmer KA, Heyman A (2008) Consortium to Establish a Registry for Alzheimer's Disease (CERAD): The first twenty years. Alzheimers Dement 4, 96-109.

[38] Warrington EK, James M (1991) The Visual Object and Space Perception Battery, Thames Valley Test Company, Bury St Edmunds, England.

[39] Reitan RM, Wolfson D (1985) The Halstead-Reitan Neuropsychological Test Battery, Neuropsychology Press, Tucson.

[40] Benton AL, Hamsher Kd (1989) Multilingual Aphasia Examination. AJA Associates, Iowa City.

[41] Kirsebom BE, Espenes R, Hessen E, Waterloo K, Harald Johnsen S, Gundersen E, Botne Sando S, Rolfseng Grøntvedt G, Timón S, Fladby T (2019) Demographically adjusted CERAD wordlist test norms in a Norwegian sample from 40 to 80 years. Clini Neuropsychol 33 (Supp 1), 27-39.

[42] Heaton RK, Miller SW, Taylor MJ, Grant I (2004) Revised Comprehensive Norms for an Expanded Halsted-Reitan Battery: Demographically Adjusted Neuropsychological Norms for African American and Caucasian Adults. Psychological Assessment Resources, Odessa.

[43] Reijs BL, Teunissen CE, Goncharenko N, Betsou F, Blennow K, Baldeiras I, Brosseron F, Cavedo E, Fladby 
T, Froelich L, Gabryelewicz T, Gurvit H, Kapaki E, Koson P, Kulic L, Lehmann S, Lewczuk P, Lleo A, Maetzler W, de Mendonca A, Miller AM, Molinuevo JL, Mollenhauer B, Parnetti L, Rot U, Schneider A, Simonsen AH, Tagliavini F, Tsolaki M, Verbeek MM, Verhey FR, Zboch M, Winblad B, Scheltens P, Zetterberg H, Visser PJ (2015) The Central Biobank and Virtual Biobank of BIOMARKAPD: A resource for studies on neurodegenerative diseases. Front Neurol 6, 216.

[44] Kalheim LF, Fladby T, Coello C, Bjrnerud A, Selnes P (2018) [18F]-Flutemetamol uptake in cortex and white matter: Comparison with cerebrospinal fluid biomarkers and [18F]-fludeoxyglucose. J Alzheimers Dis 62, 1595-1607.

[45] Sämgård K, Zetterberg H, Blennow K, Hansson O, Minthon L, Londos E (2010) Cerebrospinal fluid total tau as a marker of Alzheimer's disease intensity. Int J Geriatr Psychiatry 25, 403-410.

[46] Rami L, Fortea J, Bosch B, Sole-Padulles C, Llado A, Iranzo A, Sanchez-Valle R, Molinuevo JL (2011) Cerebrospinal fluid biomarkers and memory present distinct associations along the continuum from healthy subjects to AD patients. J Alzheimers Dis 23, 319-326.

[47] DeCarli C, Mungas D, Harvey D, Reed B, Weiner M, Chui H, Jagust W (2004) Memory impairment, but not cerebrovascular disease, predicts progression of MCI to dementia. Neurology 63, 220-227.

[48] Wolfsgruber S, Wagner M, Schmidtke K, Frolich L, Kurz A, Schulz S, Hampel H, Heuser I, Peters O, Reischies FM, Jahn H, Luckhaus C, Hull M, Gertz HJ, Schroder J, Pantel J, Rienhoff O, Ruther E, Henn F, Wiltfang J, Maier W, Kornhuber J, Jessen F (2014) Memory concerns, memory performance and risk of dementia in patients with mild cognitive impairment. PLoS One 9, e100812.

[49] Rock PL, Roiser JP, Riedel WJ, Blackwell AD (2014) Cognitive impairment in depression: A systematic review and meta-analysis. Psychol Med 44, 2029-2040.

[50] Ott CV, Bjertrup AJ, Jensen JH, Ullum H, Sjaelland R, Purdon SE, Vieta E, Kessing LV, Miskowiak KW (2016) Screening for cognitive dysfunction in unipolar depression: Validation and evaluation of objective and subjective tools. $J$ Affect Disord 190, 607-615.

[51] Motter JN, Pimontel MA, Rindskopf D, Devanand DP, Doraiswamy PM, Sneed JR (2016) Computerized cognitive training and functional recovery in major depressive disorder: A meta-analysis. J Affect Disord 189, 184-191.

[52] Baune BT, Air T (2016) Clinical, functional, and biological correlates of cognitive dimensions in major depressive disorder - rationale, design, and characteristics of the Cognitive Function and Mood Study (CoFaM-Study). Front Psychiatry 7, 150 .

[53] Beblo T, Sinnamon G, Baune BT (2011) Specifying the neuropsychology of affective disorders: Clinical, demographic and neurobiological factors. Neuropsychol Rev 21, 337-359.

[54] Drevets WC, Price JL, Furey ML (2008) Brain structural and functional abnormalities in mood disorders: Implications for neurocircuitry models of depression. Brain Struct Funct 213, 93-118.

[55] Murphy FC, Michael A, Robbins TW, Sahakian BJ (2003) Neuropsychological impairment in patients with major depressive disorder: The effects of feedback on task performance. Psychol Med 33, 455-467.

[56] Knight MJ, Baune BT (2018) Cognitive dysfunction in major depressive disorder. Curr Opin Psychiatry 31, 26-31.

[57] Davis MT, DellaGioia N, Matuskey D, Harel B, Maruff P, Pietrzak RH, Esterlis I (2017) Preliminary evidence concerning the pattern and magnitude of cognitive dysfunction in major depressive disorder using Cogstate measures. $J$ Affect Disord 218, 82-85.

[58] Plotkin DA, Mintz J, Jarvik LF (1985) Subjective memory complaints in geriatric depression. Am J Psychiatry 142, 1103-1105.

[59] Hanninen T, Reinikainen KJ, Helkala EL, Koivisto K, Mykkanen L, Laakso M, Pyorala K, Riekkinen PJ (1994) Subjective memory complaints and personality traits in normal elderly subjects. J Am Geriatr Soc 42, 1-4.

[60] Zlatar ZZ, Muniz M, Galasko D, Salmon DP (2018) Subjective cognitive decline correlates with depression symptoms and not with concurrent objective cognition in a clinic-based sample of older adults. J Gerontol B Psychol Sci Soc Sci 73, 1198-1202.

[61] Zlatar ZZ, Muniz MC, Espinoza SG, Gratianne R, Gollan TH, Galasko D, Salmon DP (2018) Subjective cognitive decline, objective cognition, and depression in older Hispanics screened for memory impairment. J Alzheimers Dis 63, 949-956.

[62] Chen X, Farrell ME, Moore W, Park DC (2019) Actual memory as a mediator of the amyloid-subjective cognitive decline relationship. Alzheimers Dement (Amst) 11, 151-160.

[63] Gifford KA, Hohman TJ, Babicz M, Logan LA, MartinWillet R, Seabolt C, Thursby M, Wiggins ME, Wisniewski KM, Jefferson AL (2016) Disentangeling depression from subjective cognitive decline in non-demented older adults: The Vanderbilt memory and aging project. Alzheimers Dement 12, P771.

[64] Ownby RL, Crocco E, Acevedo A, John V, Loewenstein D (2006) Depression and risk for Alzheimer disease: Systematic review, meta-analysis, and metaregression analysis. Arch Gen Psychiatry 63, 530-538.

[65] Leyhe T, Reynolds CF, 3rd, Melcher T, Linnemann C, Kloppel S, Blennow K, Zetterberg H, Dubois B, Lista S, Hampel $\mathrm{H}$ (2017) A common challenge in older adults: Classification, overlap, and therapy of depression and dementia. Alzheimers Dement 13, 59-71.

[66] Krell-Roesch J, Vassilaki M, Mielke MM, Kremers WK, Lowe VJ, Vemuri P, Machulda MM, Christianson TJ, Syrjanen JA, Stokin GB, Butler LM, Traber M, Jack CR, Jr., Knopman DS, Roberts RO, Petersen RC, Geda YE (2019) Cortical beta-amyloid burden, neuropsychiatric symptoms, and cognitive status: The Mayo Clinic Study of Aging. Transl Psychiatry 9, 123.

[67] Brendel M, Pogarell O, Xiong G, Delker A, Bartenstein P, Rominger A, Alzheimer's Disease Neuroimaging Initiative (2015) Depressive symptoms accelerate cognitive decline in amyloid-positive MCI patients. Eur J Nucl Med Mol Imaging 42, 716-724.

[68] Butters MA, Klunk WE, Mathis CA, Price JC, Ziolko SK, Hoge JA, Tsopelas ND, Lopresti BJ, Reynolds CF, 3rd, DeKosky ST, Meltzer CC (2008) Imaging Alzheimer pathology in late-life depression with PET and Pittsburgh Compound-B. Alzheimer Dis Assoc Disord 22, 261-268.

[69] Wu KY, Hsiao IT, Chen CS, Chen CH, Hsieh CJ, Wai YY, Chang CJ, Tseng HJ, Yen TC, Liu CY, Lin KJ (2014) Increased brain amyloid deposition in patients with a lifetime history of major depression: Evidenced on 18Fflorbetapir (AV-45/Amyvid) positron emission tomography. Eur J Nucl Med Mol Imaging 41, 714-722.

[70] Sun X, Steffens DC, Au R, Folstein M, Summergrad P, Yee J, Rosenberg I, Mwamburi DM, Qiu WQ (2008) 
Amyloid-associated depression: A prodromal depression of Alzheimer disease? Arch Gen Psychiatry 65, 542-550.

[71] Perin S, Harrington KD, Lim YY, Ellis K, Ames D, Pietrzak RH, Schembri A, Rainey-Smith S, Salvado O, Laws SM, Martins RN, Villemagne VL, Rowe CC, Masters CL, Maruff $\mathrm{P}$ (2018) Amyloid burden and incident depressive symptoms in preclinical Alzheimer's disease. J Affect Disord 229, 269274.

[72] Donovan NJ, Hsu DC, Dagley AS, Schultz AP, Amariglio RE, Mormino EC, Okereke OI, Rentz DM, Johnson KA, Sperling RA, Marshall GA (2015) Depressive symptoms and biomarkers of Alzheimer's disease in cognitively normal older adults. $J$ Alzheimers Dis 46, 63-73.

[73] Reid LM, Maclullich AM (2006) Subjective memory complaints and cognitive impairment in older people. Dement Geriatr Cogn Disord 22, 471-485.

[74] Slavin MJ, Brodaty H, Kochan NA, Crawford JD, Trollor JN, Draper B, Sachdev PS (2010) Prevalence and predictors of "subjective cognitive complaints" in the Sydney Memory and Ageing Study. Am J Geriatr Psychiatry 18, 701-710.

[75] Buckley R, Saling MM, Ames D, Rowe CC, Lautenschlager NT, Macaulay SL, Martins RN, Masters CL, O'Meara T, Savage G, Szoeke C, Villemagne VL, Ellis KA (2013) Factors affecting subjective memory complaints in the AIBL aging study: Biomarkers, memory, affect, and age. Int Psychogeriatr 25, 1307-1315.

[76] Heser K, Tebarth F, Wiese B, Eisele M, Bickel H, Kohler M, Mosch E, Weyerer S, Werle J, Konig HH, Leicht H,
Pentzek M, Fuchs A, Riedel-Heller SG, Luppa M, Prokein J, Scherer M, Maier W, Wagner M (2013) Age of major depression onset, depressive symptoms, and risk for subsequent dementia: Results of the German study on Ageing, Cognition, and Dementia in Primary Care Patients (AgeCoDe). Psychol Med 43, 1597-1610.

[77] Jessen F, Wiese B, Bachmann C, Eifflaender-Gorfer S, Haller F, Kolsch H, Luck T, Mosch E, van den Bussche H, Wagner M, Wollny A, Zimmermann T, Pentzek M, RiedelHeller SG, Romberg HP, Weyerer S, Kaduszkiewicz H, Maier W, Bickel H (2010) Prediction of dementia by subjective memory impairment: Effects of severity and temporal association with cognitive impairment. Arch Gen Psychiatry 67, 414-422.

[78] Fujishiro H (2019) Early diagnosis of Lewy body disease in elderly individuals with subjective cognitive decline. $J$ Neurol Sci 401, 128-129.

[79] Harada CN, Natelson Love MC, Triebel KL (2013) Normal cognitive aging. Clin Geriatr Med 29, 737-752.

[80] Slavin MJ, Sachdev PS, Kochan NA, Woolf C, Crawford JD, Giskes K, Reppermund S, Trollor JN, Draper B, Delbaere K, Brodaty H (2015) Predicting cognitive, functional, and diagnostic change over 4 years using baseline subjective cognitive complaints in the Sydney Memory and Ageing Study. Am J Geriatr Psychiatry 23, 906-914.

[81] Werner P, Goldstein D, Karpas DS, Chan L, Lai C (2014) Help-seeking for dementia. Alzheimer Dis Assoc Disord 28 , 299-310. 